\title{
A paper-based competitive lateral flow immunoassay for multi $\beta$-agonist residues by using a single monoclonal antibody labelled with red fluorescent nanoparticles
}

\author{
Ruiguo Wang ${ }^{1,2} \cdot$ Wei Zhang ${ }^{1,2} \cdot$ Peilong Wang ${ }^{1,2} \cdot$ Xiaoou Su $^{1,2}$
}

Received: 29 November 2017 / Accepted: 10 February 2018 / Published online: 22 February 2018

(C) The Author(s) 2018. This article is an open access publication

\begin{abstract}
An ultrasensitive paper based lateral flow assay is described for rapid and simultaneous fluorometric detection of several $\beta$-agonists including clenbuterol and its chemical analogues (mabuterol, brombuterol, cimaterol, cimbuterol, bromchlorbuterol and banbuterol). A nonspecific monoclonal antibody (mAb) against clenbuterol and its analogues was prepared and employed in a competitive immunoassay where $\mathrm{mAb}$ conjugated to fluorescent nanoparticles and free $\beta$-agonists compete for the binding sites. This enables rapid screening for the $7 \beta$-agonists in a single run that takes about $8 \mathrm{~min}$. Detection limits for the seven $\beta$-agonists are $<50 \mathrm{pg} \mathrm{g}^{-1}$ of pork. Recoveries ranged from $69.5 \%$ to $102.4 \%$, and relative standard deviations were $\pm 15 \%$. The assay was applied to the analysis of both using spiked and unspiked pork for $\beta$-agonists, and the results compare well to those obtained by HPLC-MS.
\end{abstract}

Keywords $\beta$-Agonist $\cdot$ Fluorescent nanoparticles $\cdot$ Paper-based assay $\cdot$ Immunoassay $\cdot$ Multi residues $\cdot$ Pork tissue

\section{Introduction}

$\beta$-Agonists are a family of synthetic phenylethanolamine compounds used for treatment of human pulmonary disease and asthma. They can be divided into 3 groups with different aromatic core structure: aniline, phenol and resorcinol [1]. $\beta$ Agonists promote the growth and nutrient repartition for swine, cow and other livestock [2]. Residues of $\beta$-agonists carried over by feed or drinking water can lead to hazard effects on human health [3]. Hence, $\beta$-agonists have been banned as growth promoters in the European Union [4] and China [5]. Therefore, sensitive, broad screening and

Electronic supplementary material The online version of this article (https://doi.org/10.1007/s00604-018-2730-9) contains supplementary material, which is available to authorized users.

Peilong Wang

wplcon99@163.com

$\triangle$ Xiaoou $\mathrm{Su}$

suxiaoou@caas.cn

1 Key Laboratory of Agro-product Safety and Quality, Ministry of Agriculture, Beijing 100081, People's Republic of China

2 Institute of Quality Standards \& Testing Technology for Agro-Products, Chinese Academy of Agricultural Sciences, Beijing 100081, People's Republic of China convenient assays are needed for onsite detection of trace residues of $\beta$-agonists.

Several analytical techniques based on expensive instrument, such as liquid chromatography (LC) $[6,7]$, gas chromatography-mass spectrometry (GC-MS) [8], LCtandem mass spectrometry (LC-MS/MS) [9], GC-MS/MS [1] and capillary electrophoresis [10], have been applied into detect trace amount of $\beta$-agonist residues in various samples. Above methods are complicated and laborious because they involve time-consuming sample preparation and chromatographic separation procedures. Some novel sample preparation such as molecularly imprinted polymer was used [11] to improve clean-up, but the procedure was still time consuming. Enzyme immunoassay [12] and radio-immunoassay [13] didn't require expensive instruments, but the incubation and washing procedures were complicated. Currently, some novel analytical method, such as electrochemical sensors [14], micro fluidic chips [15], surface-enhanced Raman scattering immunoassay [16], sensitive visual probes $[17,18]$, and dualresponsive fluorescence [19] have been developed. Cao et al. [20] have developed the novel immuno sensor for clenbuterol (CLEN) by coupling purification and in situ immobilization process of monoclonal antibodies. However, these newly developed methods were subjected to either single component detection or lower sensitivity, which don't meet 
the demand of emerging requirements of broad screening and onsite detection.

Paper has become a simple, flexible, and reliable platform for analytical devices. One of the most familiar applications of paper based analytical devices is a lateral flow immuno assay (LFIA), which is broadly used into detection of small molecules and biomarkers [21]. Compared with conventional detection methods, LFIA offers advantages such as low cost, mutable fabrication and speed. The most usually used format of LFIA is the employment of colloidal gold as reporters for colorimetric detection, which can realize qualitative or semi quantitative analysis of the target analytes. However, such format of LFIA can only be used for analyzing target analytes with relatively high concentrations. Colloidal gold based LFIA has been applied to the qualitative detection of CLEN and salbutamol (SAL) $[22,23]$. In order to improve sensitivity of LFIA for $\beta$-agonists, labels such as $\mathrm{Ru}(\text { phen })_{3}{ }^{2+}$ doped silica nanoparticle [24] and fluorescent nano silica [25], have been employed in LFIA fabrication. In 2015, we have developed a fluorescent beads based multi component LFIA method for simultaneous detection of CLEN, ractopamine (RAC) and SAL in feed, urine and tissue samples with higher sensitivity (as low as $0.1 \mathrm{ng} \mathrm{mL}^{-1}$ ) [26]. It provided a promising fabrication strategy of multi-component LFIA method. However, the task is daunting as there are many kinds of $\beta$ agonist drugs existing in various types of sample matrices such as animal feed, tissue and body fluids. Most of the published LFIA methods for $\beta$-agonist detection were limited to no more than three analytes due to capacity of the testing strip and limited degree of cross-reactivity of the antibodies.

In this study, we report a one-step fluorescent lateral flow immunoassay (FLFIA) which can realize screening or semi quantification of CLEN and its structural analogues (See Electronic Supplementary Material Fig. S1), including mabuterol (MAB), brombuterol (BBT), cimaterol (CMT), cimbuterol (CBT), bromchlorbuterol (BCT) and banbuterol (BAN). The method utilizes a high performance antibody with high cross reactivity that can detect trace amounts of seven kinds of $\beta$-agonist residue in pork tissue samples. Limits of detection (LODs) as low as $0.05 \mathrm{ng} \cdot \mathrm{mL}^{-1}$ (or $\mathrm{ng}$. $\mathrm{g}^{-1}$ ) can be achieved. With the FLFIA assay, ultra sensitive, large scale and high speed screening of illicit $\beta$-agonist can be realized in the field with a low cost comparable to colloid gold testing strips currently in practice.

\section{Experimental}

\section{Regents and apparatus}

CLEN, MAB, BBT, CMT, CBT, BCT, BAN, RAC, SAL, fenoterol, tulobuterol, epinephrine, dopamine and other compounds such as penicillin, ampicillin, kanamycin and ciprofloxacin were purchased from Sigma-Aldrich (St. Louis, USA. https://www.sigmaaldrich.com/). The high cross reactive monoclonal antibody (HCR-mAb) of $\beta$ agonist $\left(13 \mathrm{mg} \mathrm{mL}^{-1}\right)$ and the corresponding antigen (CLEN-BSA, the valence of antigen was about 5000) were jointly developed by our laboratory and Beijing Kingbown Bio-tech LTD (http://www.kwinbon.com/). The rabbit antimouse immunoglobulin ( $\mathrm{IgG}$ ) was also from Beijing Kingbown Bio-tech LTD (http://www.kwinbon.com/). Fluorescent carboxy modified latex nanoparticles (F8810, particle size $200 \mathrm{~nm}$, excitation best at $580 \mathrm{~nm}$; enission peak at $605 \mathrm{~nm}$ ) were purchased from Life Technologies, USA (https://www.thermofisher.com/cn/zh/home/brands/ life-technologies.html).

Water was obtained from a Milli Q purification system (Millipore, http://www.merckmillipore.com/). All other chemicals were of analytical grade or better. Nitrocellulose (NC) membranes (CN95, pore size is $15 \mu \mathrm{m}$ ) were from Sartorius (Göttingen, Germany. https://www.sartorius.com. cn). Glass fibers and absorbent pads were obtained from Millipore Corporation (Bedford, USA. http://www. merckmillipore.com/). ZX 1010 Dispensing Platform, LM8030 Batch Laminator and CM4000 Guillotine Cutter from BioDot (Irvine, USA. https://www.biodot.com/) were used to prepare test strips. Fluorescence was detected by a special fluorescence photometer (BT-211D, $30 \mathrm{~cm} \times 20$ $\mathrm{cm} \times 12 \mathrm{~cm}$ ) provided by Beijing Zhifeng Botai Bio-tech Ltd.

\section{Preparation of the fluorescent lateral flow immunoassay (FLFIA)}

Structure of the test stripe is shown in Fig. 1a. Conjugate pads and sample pads were made from glass fiber. They were treated with blocking buffer $(0.01 \mathrm{M}$ phosphate buffer $(\mathrm{pH}=7.4)$ containing $2 \%$ OVA, $2 \%$ sucrose and $0.02 \%$ $\mathrm{NaN}_{3}$ ) and dried at $37^{\circ} \mathrm{C}$ over night. The HCR-mAb-FB conjugate was dispensed onto the conjugate pad with the BioDot jet printer and dried. The antigen CLEN-BSA $(1 \mathrm{mg} / \mathrm{mL})$ and rabbit $\mathrm{IgG}$ were coated on NC membrane as testing line and control line by using a BioDot jet printer with proper rate. After drying at $37{ }^{\circ} \mathrm{C}$ for $1 \mathrm{~h}$, the $\mathrm{NC}$ membranes were stored in a desiccator. The NC membrane, conjugate pad, sample pad and absorbent pad were laminated and glued to a plastic backing. Then, the assembled pads were cut into strips $(0.4 \mathrm{~cm} \times 6.0 \mathrm{~cm})$, which were installed in dip stick shell and stored in desiccator at room temperature until use.

\section{Immunoassay procedure}

For the immunoassay, about $60 \mu \mathrm{L}$ of $\beta$-agonist standard or extracted sample solution was loaded onto the sample pad of the stripe. With the aid of the absorbent pad, the liquid 

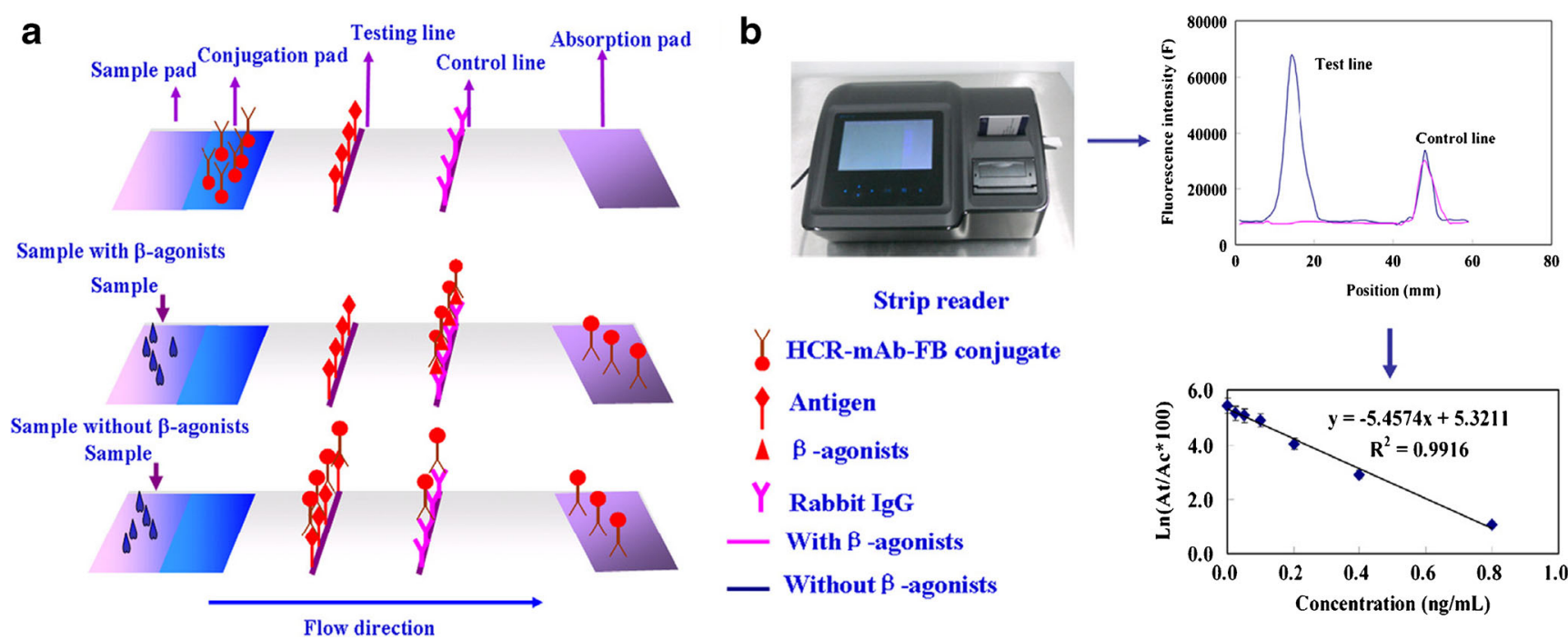

Strip reader
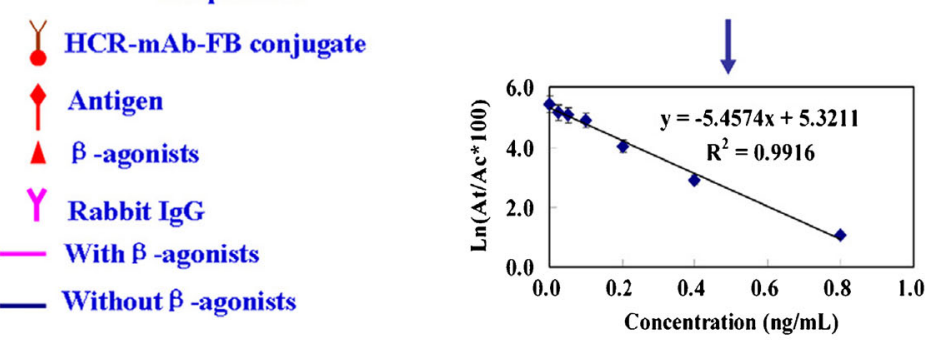

Fig. 1 a Schematic of the fluorescent lateral flow immunoassay (FLFIA) and the immunoassay procedure for samples. b Typical results and calibration curve with FLFIA strip reader

moved along the NC membrane. $\beta$-agonists in the sample reacted with HCR-mAb-FB conjugates in the conjugate zone. When there were no $\beta$-agonists in the sample, all HCR-mAb-FBs reach the test line and can be captured by the immobilized antigen, which resulted in fluorescence at the highest intensity (Fig. 1a). If there were $\beta$-agonists in the sample solution, the HCR-mAb-FBs were occupied by their corresponding $\beta$-agonists, and cannot be captured by the immobilized antigen, which resulted in reduced fluorescence intensity. After reaction, fluorescence from the immobilized HCR-mAb-FBs can be detected by a scanning fluorescence photometer and a calibration curve can thus be obtained (Fig. 1b).

\section{Sample pretreatment}

For pretreatment of pork tissue samples, $1 \mathrm{~g}$ ground pork was weighed and mixed with $2 \mathrm{~mL}$ phosphate buffer in a $10 \mathrm{~mL}$ plastic centrifuge tube. After homogenate with homogenizer (IKA, Germany), the tube was centrifuged for $5 \mathrm{~min}$ at $10000 \mathrm{rpm}$ and the supernatant was collected for FLFIA analysis.

\section{Fluorescence detection}

Fluorescence of immobilized FB-mAbs on test line and control line of the strip was detected by a scanning fluorescence photometer. The strip was inserted into sample holder of the fluorescence photometer and the scan head of the photometer moves along the reading zone of the FLFIA strip, where the test lines and control line were scanned in sequence. The fluorescent signals of test line and control line was obtained for calculating detection results.

\section{Method validation}

The validity of the method was verified by analyzing pork tissue samples individually spiked with seven kinds of $\beta$ agonist at different levels. The results of real contaminated pork tissue samples which were from China National Feed Quality Control Center (Beijing), were used to further validate and compare with results from ultra performance liquid chromatography coupled tandem mass spectrometry.

\section{Results and discussion}

\section{Evaluation of HCR-mAb for $\beta$-agonists}

Antibody plays a crucial role in the method. In this study, the production method of the HCR-mAb was similar with the published method [27]. Briefly, CLEN was linked to BSA and then used as immunogen. The immunogen of CLEN-BSA was injected into Balb/c mice and each mouse was given $150 \mu \mathrm{g}$ of immunogen subcutaneously in Freund's complete adjuvant to produce antisera. After the fusion and hybrid selection of the spleen cells from mice and SP2/0 bone marrow tumor cells at proper ratio $(8: 1)$ to achieve the hybrid tumor cell line of monoclonal antibody. For the production and purification of HCR-mAb, the sterilization paraffin oil was injected into abdominal cavity of the Balb/c mice. After 7 days, each mouse was given $4 \times 10^{5}$ of recovery hybrid tumor cell line. The ascitic fluid from the mice was accumulated after 7 days and then was purified to achieve the mAb against aniline $\beta$-agonists. Furthermore, the performance of the novel HCR-mAb of the immunoassay such as sensitivity and specificity was 
examined in detail. The results of half maximal inhibitory concentration (IC50) and cross reactivity (CR) were listed in Table S1. The results indicated that the HCR$\mathrm{mAb}$ has excellent sensitivity and specificity towards aniline $\beta$-agonists such as CLEN, MAB, BAN, BBT, CMT, CBT and BCT. Especially for CMT, CBT and BCT, IC50 values as low as $0.09 \mathrm{ng} \cdot \mathrm{mL}^{-1}$ can be achieved. The novel HCR-mAb showed much lower sensitivity towards phenol and resorcinol $\beta$-agonists such as RAC, SAL, fenoterol, tulobuterol and other veterinary drugs. Typical IC50 values for concentrations of competitor drug were above $100 \mathrm{ng} \cdot \mathrm{mL}^{-1}$. In addition, cross reaction experiments showed that the HCR-mAb can only recognize $\beta$-agonists containing aniline group with high specificity. For the antibiotic compounds, the CR of the developed HCR-mAb was lower than $0.013 \%$. For other $\beta$ agonists containing phenol and resorcinol such as RAC, SAL, fenoterol and tulobuterol, the CR was only $0.13 \%$. Even for the natural compounds such as epinephrine and dopamine, the CR was below $0.065 \%$. The $\mathrm{CR}$ results indicated that the HCR mAb possessed satisfactory specificity for aniline group $\beta$-agonists, it enabled high through screening for aniline group $\beta$-agonists even though with presence of natural compounds like $\beta$ -
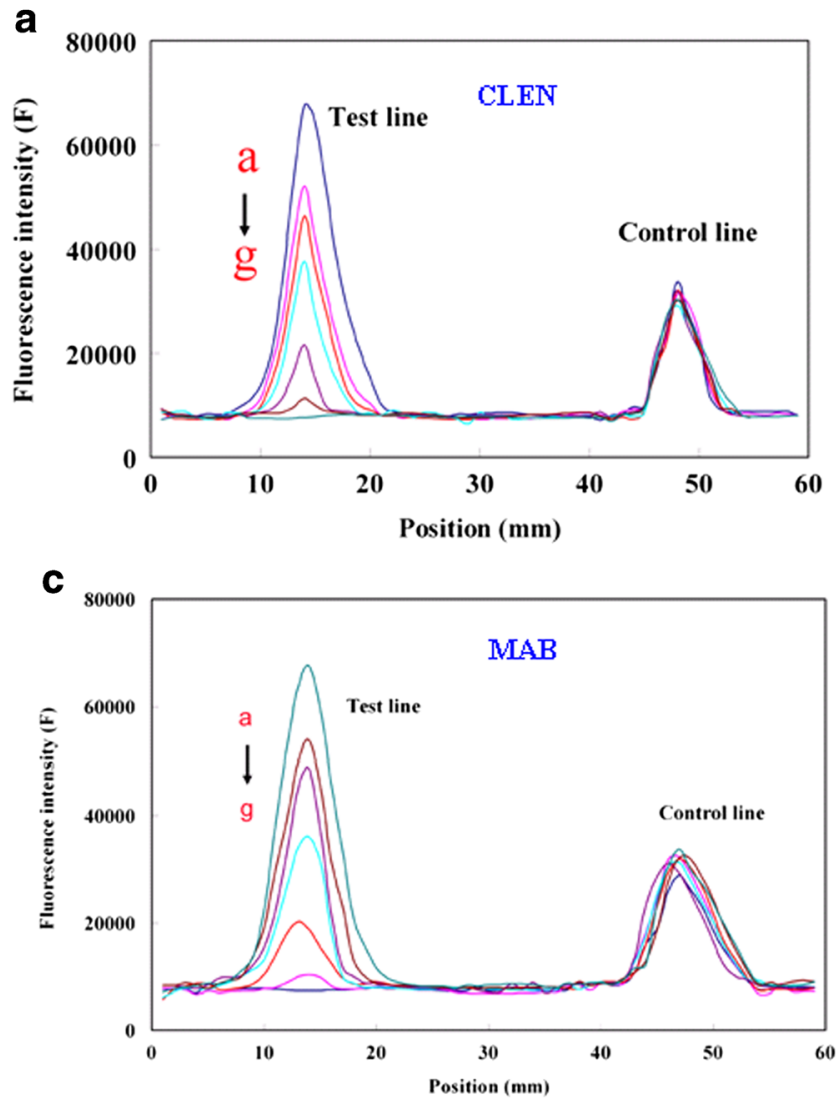

Fig. 2 a Fluorescence intensity corresponding to $0 \mathrm{ng} / \mathrm{mL}, 0.025 \mathrm{ng} / \mathrm{mL}$, $0.05 \mathrm{ng} / \mathrm{mL}, 0.1 \mathrm{ng} / \mathrm{mL}, 0.2 \mathrm{ng} / \mathrm{mL}, 0.4 \mathrm{ng} / \mathrm{mL}$ and $0.8 \mathrm{ng} / \mathrm{mL}$ of CLEN (curves a-g, Ex $580 \mathrm{~nm}$ and Em $605 \mathrm{~nm}$ ) (b) Calibration curve of CLEN. agonist such as epinephrine and dopamine. For the cross reactivity improvement of $\mathrm{HCR}-\mathrm{mAb}$, it was speculated that the active site of the novel HCR-mAb was specific for aniline $\beta$-agonist due to the active site on the HCR$\mathrm{mAb}$ can selectively bind aniline on the benzene ring of $\beta$-agonist.

\section{Optimization of HCR-mAb-FB conjugate preparation}

In accordance with our previous study [26], carboxylate modified FB was first activated in 0.01 M MEST buffer $(\mathrm{pH}=5.0)$ for $10 \mathrm{~min}$, then reacted with certain concentration of HCR-mAb in phosphate buffer $\left(0.01 \mathrm{~mol} \mathrm{~L}^{-1}\right)$. The optimal concentration of HCR-mAb for FBs labeling was obtained using "trial and error" method. HCR-mAb solution at concentrations of $1.0 \mathrm{mg} \mathrm{mL}^{-1}, 2.0 \mathrm{mg} \mathrm{mL}^{-1}$ and $4.0 \mathrm{mg} \mathrm{mL}^{-1}$ were examined and it was found that sensitivity of the detection system was highest at $2.0 \mathrm{mg}$ $\mathrm{mL}^{-1}$ and the volume of the HCR-mAb solution was 100 $\mu \mathrm{L}$. In addition, fluorescence of the FBs did not show any shift after surface modification, the excitation wavelength was still $580 \mathrm{~nm}$ and the emission wavelength was $605 \mathrm{~nm}$.
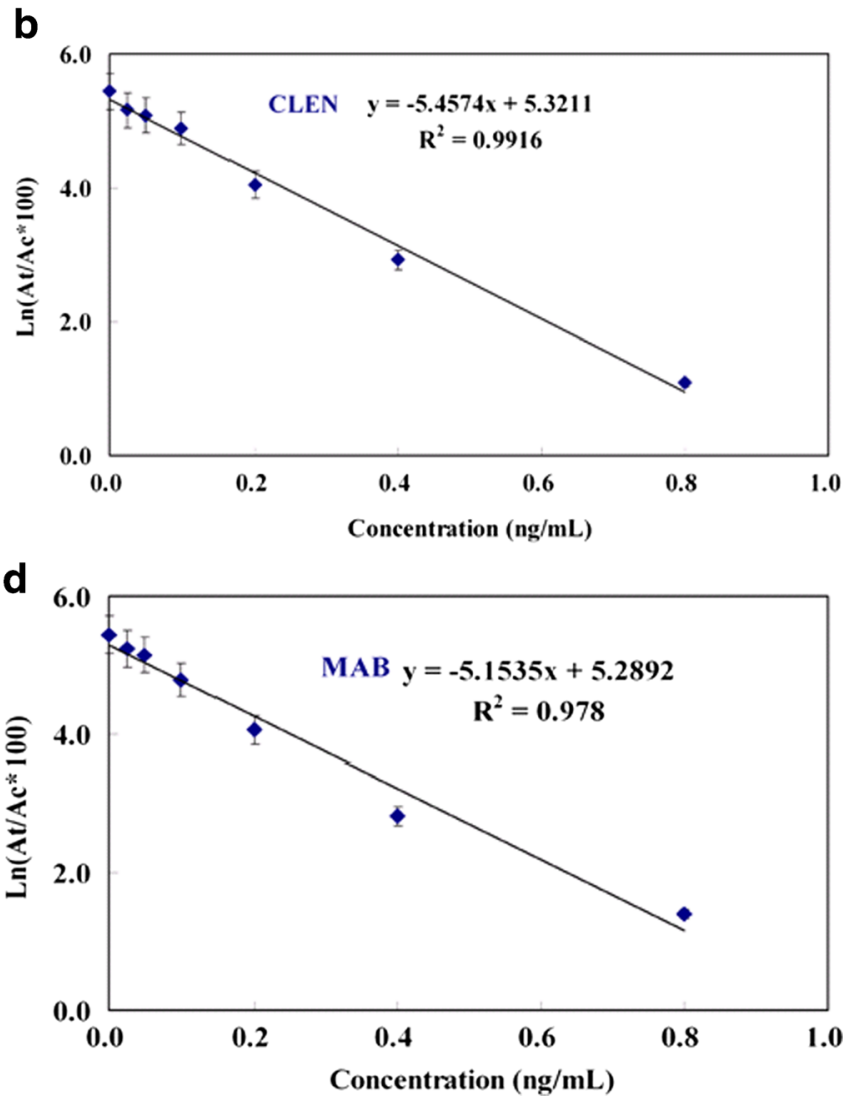

c Fluorescence intensity corresponding to $0 \mathrm{ng} / \mathrm{mL}, 0.025 \mathrm{ng} / \mathrm{mL}$, $0.05 \mathrm{ng} / \mathrm{mL}, 0.1 \mathrm{ng} / \mathrm{mL}, 0.2 \mathrm{ng} / \mathrm{mL}, 0.4 \mathrm{ng} / \mathrm{mL}$ and $0.8 \mathrm{ng} / \mathrm{mL}$ of MAB (curves a-g, Ex $580 \mathrm{~nm}$ and Em $605 \mathrm{~nm}$ ) (d) Calibration curve of MAB 


\section{Optimization of the fabrication of the strip for the lateral flow immuno assay}

In the previous study [26], we optimized crucial parameters of strip, such as blocking buffer and NC membrane, to achieve best sensitivity and specificity.

Here, the amount of HCR-mAb-FB and CLEN-BSA antigen was focused and optimized. The amount of HCR-mAbFB loaded on the glass fiber can seriously influence the final fluorescence intensity at the test and control line on the strip. Stock HCR-mAb-FB solution was diluted by 10 -fold, 50 -fold and 80 fold. The 50-fold dilution, which accounts of a HCRmAb-FB surface coverage of $70 \mu \mathrm{L} \mathrm{cm}^{-2}$ was found to provide the best sensitivity with low interference fluorescence signals. The amount of CLEN-BSA antigen was evaluated with "checker-board titration" in ELISA. Finally, the optimal amounts for antigen of CLEN-BSA used for the test lines were $1000 \mathrm{ng} \mathrm{cm}^{-1}$.

\section{Evaluation of the method}

\section{Reaction time}

For the HCR-mAb-FB, it takes time to react and diffuse through the $\mathrm{NC}$ membrane after loading sample solution to reach the test line and the control line in the reading zone. The reaction time was optimized using the blank phosphate buffer. The test strip was placed into the photometer and the fluorescence signal from the test line and control line was got at various time intervals. The fluorescence signals of the HCR$\mathrm{mAb}-\mathrm{FB}$ on test line and control line reached plateau after 6 min of incubation (Fig. S2). In order to ensure completeness of the reaction and reproducibility of the data, 8 min was selected as the final reaction time.

\section{Analytical performance of the strip}

As a competitive assay, the fluorescence intensity measured by the photometer decreases with increasing target $\beta$-agonist concentration and a logarithm relationship is observed. The fluorescence signal under different concentrations of CLEN and MAB from $0.0 \mathrm{ng} \cdot \mathrm{mL}^{-1}$ to $0.8 \mathrm{ng} \cdot \mathrm{mL}^{-1}$ was obtained (Fig. 2a, c), the correlation coefficient $\left(\mathrm{R}^{2}\right)$ for CLEN and MAB was 0.9916 and 0.978 , respectively (Fig. $2 b$, d). Five other target $\beta$-agonists showed similar behavior (See Table S2).

LODs for the $7 \beta$-agonists are estimated to be lower than $0.05 \mathrm{ng} \cdot \mathrm{mL}^{-1}$ (Table S2). Especially for CMT, an LOD as low as $0.01 \mathrm{ng} \cdot \mathrm{mL}^{-1}$ is achieved. The limits of quantification (LOQs) for screening of all target aniline $\beta$-agonists are estimated to be $0.1 \mathrm{ng} \cdot \mathrm{mL}^{-1}\left(\mathrm{ng} \mathrm{g}^{-1}\right)$, in which took the dilution fold of sample preparation into account. The LODs of the high throughput strip assay are far better than that of the colloidal gold or fluorescent-based strip method and the LOQs of the
FLFIA method can meet the strict minimum residue of limited (MRL) requirement of $0.1 \mathrm{ng} / \mathrm{mL}$ for $\mathrm{EU}$.

\section{Interferences tolerance for sample matrix}

In order to achieve sensitive and specific detection of real samples, it is essential to evaluate interference tolerance of the broadscreening FLFIA method for sample matrix. Animal tissue (pork, veal and steak) were collected to validate specificity of the FLFIA. The results showed that the sample matrices of edible animal tissue had minimum interference on the FLFIA strip after dilution. Due to high sensitivity of the assay, after 2 fold dilution, the assay can still meet or exceed LOD requirement of most standards currently in use in China and EU.

\section{Accuracy of the method}

Accuracy of the fluorometric lateral flow immunoassay for broad screening was tested with pork tissue samples spiked with target $\beta$-agonists. $1 \mathrm{~g}$ of tissue spiked with CLEN, MAB, BAN, $\mathrm{BBT}, \mathrm{CMT}, \mathrm{CBT}$ and $\mathrm{BCT}$ ranging from $0.2 \mathrm{ng}$ to $1.0 \mathrm{ng}$. The results are listed in Table 1. Recoveries of CLEN, MAB, BAN,

Table 1 Recovery of $\beta$-agonist individually added to pork tissue samples by using the fluorometric lateral flow immunoassay (FLFIA) method. $(n=6)$

\begin{tabular}{|c|c|c|c|}
\hline \multirow[t]{2}{*}{ Analytes } & \multicolumn{3}{|c|}{ Pork tissue (ng/g) } \\
\hline & Added & Found & Recovery (\%) \\
\hline \multirow[t]{3}{*}{ CLEN } & 0.2 & 0.174 & $87.0 \pm 8.2$ \\
\hline & 0.4 & 0.345 & $86.3 \pm 6.5$ \\
\hline & 1.0 & 1.024 & $102.4 \pm 4.3$ \\
\hline \multirow[t]{3}{*}{ MAB } & 0.2 & 0.165 & $83.5 \pm 9.7$ \\
\hline & 0.4 & 0.326 & $81.5 \pm 6.6$ \\
\hline & 1.0 & 0.896 & $89.6 \pm 5.8$ \\
\hline \multirow[t]{3}{*}{ BAN } & 0.2 & 0.139 & $69.5 \pm 8.0$ \\
\hline & 0.4 & 0.315 & $78.8 \pm 5.1$ \\
\hline & 1.0 & 0.857 & $85.7 \pm 4.7$ \\
\hline \multirow[t]{3}{*}{$\mathrm{BBT}$} & 0.2 & 0.138 & $69.0 \pm 7.2$ \\
\hline & 0.4 & 0.358 & $89.5 \pm 5.0$ \\
\hline & 1.0 & 0.938 & $93.8 \pm 6.6$ \\
\hline \multirow[t]{3}{*}{ BCT } & 0.2 & 0.153 & $76.5 \pm 8.8$ \\
\hline & 0.4 & 0.383 & $95.8 \pm 4.9$ \\
\hline & 1.0 & 0.927 & $92.7 \pm 5.2$ \\
\hline \multirow[t]{3}{*}{ CMT } & 0.2 & 0.167 & $83.5 \pm 5.9$ \\
\hline & 0.4 & 0.319 & $79.8 \pm 3.8$ \\
\hline & 1.0 & 0.874 & $87.4 \pm 2.9$ \\
\hline \multirow[t]{3}{*}{ CBT } & 0.2 & 0.179 & $89.5 \pm 8.6$ \\
\hline & 0.4 & 0.348 & $87.0 \pm 3.3$ \\
\hline & 1.0 & 0.952 & $95.2 \pm 4.3$ \\
\hline
\end{tabular}


Table 2 Comparison of immunoassays for $\beta$-agonists

\begin{tabular}{|c|c|c|c|c|c|c|c|}
\hline Compounds & Method & Sample & Analysis of flux & \multicolumn{3}{|c|}{ LOD (ng/g) } & Reference \\
\hline CLEN & ELISA & $\begin{array}{l}\text { Urine } \\
\text { Liver }\end{array}$ & Single & \multicolumn{3}{|c|}{0.2} & {$[12]$} \\
\hline SAL & LFIA & Urine & Single & \multicolumn{3}{|c|}{0.16} & {$[24]$} \\
\hline CLEN & LFIA & Urine & Single & \multicolumn{3}{|c|}{0.037} & {$[25]$} \\
\hline \multirow[t]{3}{*}{$\beta$-Agonists } & \multirow[t]{3}{*}{ Fluorescent LFIA } & Urine & Multi-residues & CLEN & & 0.10 & {$[26]$} \\
\hline & & Tissue & & $\mathrm{RAC}$ & & 0.10 & \\
\hline & & Feed & & SAL & & 0.09 & \\
\hline \multirow[t]{2}{*}{$\beta$-Agonists } & \multirow[t]{2}{*}{ LFIA } & \multirow[t]{2}{*}{ Urine } & \multirow[t]{2}{*}{ Multi-residues } & CLEN & & 1.0 & [29] \\
\hline & & & & RAC & & 1.0 & \\
\hline Brombuterol & Electrochemiluminescence immunosensor & $\begin{array}{l}\text { Tissue } \\
\text { Feed }\end{array}$ & Single & & $3.7 \times 10^{-5}$ & & {$[30]$} \\
\hline Brombuterol & LFIA & $\begin{array}{l}\text { Tissue } \\
\text { Urine }\end{array}$ & Single & & 0.38 & & {$[31]$} \\
\hline \multirow[t]{6}{*}{$\beta$-Agonists } & \multirow[t]{6}{*}{ Fluorometric lateral flow immunoassay (FLFIA) } & \multirow[t]{6}{*}{ Tissue } & \multirow[t]{6}{*}{ Broad screening } & $\begin{array}{l}\text { CLEN } \\
\text { CMT }\end{array}$ & & $\begin{array}{l}0.025 \\
0.01\end{array}$ & This method \\
\hline & & & & CBT & & 0.025 & \\
\hline & & & & MAB & & 0.025 & \\
\hline & & & & BBT & & 0.05 & \\
\hline & & & & $\mathrm{BCT}$ & & 0.025 & \\
\hline & & & & BAN & & 0.05 & \\
\hline
\end{tabular}

BBT, CMT, CBT and BCT in pork tissue samples are ranged from $69.5 \%$ to $102.4 \%$, and the relative standard deviations (RSDs) are below 12\%, thus, CLEN, MAB, BAN, BBT, $\mathrm{CMT}$, CBT and BCT in pork tissue can be quantitative determined, and the accuracy and repeatability is satisfactory.

Performance of the method for the detection of $\beta$ agonists in the presence of other $\beta$-agonists (eg. RAC, $\mathrm{SAL}$ ) in swine urine was also evaluated. A $1 \mathrm{~mL}$ sample of blank swine urine was spiked with $0.1 \mathrm{ng}$ of CLEN, CMT, MAB, CLEN/CMT and CLEN/CMT/MAB, respectively. RAC and SAL were also added into the spiked urine samples. The concentrations of RAC and SAL were $1.0 \mathrm{ng} / \mathrm{mL}$, respectively. The presence of RAC and SAL show no interference on fluorescence signal of CLEN, CMT, MAB, CLEN/CMT and CLEN/CMT/MAB (Fig. S3) and the recovery of CLEN, CMT and MAB in pork tissue samples are from $87.3 \%$ to $92.7 \%$. The results are also cross validated with LC-MS/MS. Other possible compounds such as antibiotic including penicillin, ampicillin, kanamycin and ciprofloxacin etc. showed no interference, too. It is noted that the sample spiked with mixed target $\beta$-agonists, such as CLEN/CMT and CLEN/CMT/ MAB only qualitative determination can be achieved. However, if with the presence of mixed target $\beta$-agonists, the fluorescent signal of the FLFIA can significantly reduce with the increase of the types of target $\beta$-agonists. Therefore, it is demonstrated that the FLFIA method can perform broad screening of target $\beta$-agonists in real samples. Further, the accurate amount of each compound should be determined by LC-MS/MS.

\section{Stability of the method}

For stability test, tests strip from the same batch were tested during a 3-month period. The strips were stored at room temperature. 10 strips were selected each month and tested with phosphate buffer spiked with $0.2 \mathrm{ng} \cdot \mathrm{mL}^{-1}$ of CLEN. The FLFIA strip shows no degradation in performance during 3 months of storage, RSD of the test results for CLEN is 9.3\%. Thus, the FLFIA strips show good stability in the long-term test.

\section{Comparison of analytical performance with published methods}

A series of immunoassay methods such as ELISA [12], electrochemical sensors [14], time-resolved chemiluminescence [28] and LFIA [29] have been reported for multi-residue analysis of $\beta$-agonists. LFIA method is very convenient and more suitable for field screening. Most of the reported LFIAs for $\beta$ agonist can analyze only one target analyte [22, 25]. Some multi-component LFIAs have been developed, which can analyze two or three kinds of $\beta$-agonist simultaneously $[26,28]$. But none of the LFIA based method can provide broad 
screening for seven kinds of $\beta$-agonist with lowest LODs (0.01 ng. $\mathrm{mL}^{-1}$ for CMT). Here, the performance of different types of ELISA and LFIA methods were compared (Table 2), the advantages in terms of broad-screening are obvious: (1) a novel HCR-mAb was applied to develop the broadest screening method for seven kinds of $\beta$-agonist in a single test so far. (2) The sensitivity of the FLFIA method is highest and the LOD is as the lowest as $0.01 \mathrm{ng} \cdot \mathrm{mL}^{-1}$ (for CMT). (3) The method was validated to be suitable for pork tissue samples. (4) It is fast, easy to operate and low cost.

\section{Application of the method}

Two contaminated real tissue samples were tested using the method and the results were compared with LC-MS/MS [32]. As listed in Table S3, the semi quantification results of the method are in good agreement with the reference LC-MS/MS method.

\section{Conclusion}

The multi-component FLFIA demonstrated good performances in terms of sensitivity, linearity, reproducibility and accuracy, for simultaneous determination of seven kinds of $\beta$-agonist in the real samples. All $\beta$-agonists can be quantitatively detected on a single strip within $8 \mathrm{~min}$ with a low-cost instrument. The LOD of the $7 \beta$-agonists that was lower than $0.05 \mathrm{ng} \cdot \mathrm{mL}^{-1}$ can be achieved. Furthermore, we provided a high performance antibody for more kinds of $\beta$-agonist and it can be used to develop high flux and sensitive assay method, such as electrochemical assay etc. Overall, the nanoparticle based strip combined with high performance antibody can be a potential alternative format of the ICA strip for rapid, sensitive and broad spectrum on-site detection of CLEN and its structural analogues as well as for other hazardous substances in screening applications and a variety of other biomedical applications. However, there are so many types of illicit drugs that might exist in animal feed, edible tissue and other sample matrices. Therefore, further study should focus on the development of multi-class assay for interesting hazardous compounds on one strip assay.

Acknowledgements The authors would like to thank the China National Key R\&D Program (2017YFC1601604), NSFC (No.21777189), and the International Cooperation Program (2012DFA31140) for financially supporting this research.

\section{Compliance with ethical standards}

The author(s) declare that they have no competing interests.
Open Access This article is distributed under the terms of the Creative Commons Attribution 4.0 International License (http:// creativecommons.org/licenses/by/4.0/), which permits unrestricted use, distribution, and reproduction in any medium, provided you give appropriate credit to the original author(s) and the source, provide a link to the Creative Commons license, and indicate if changes were made.

\section{References}

1. Bocca B, Fiori M, Cartoni C, Brambilla G (2003) Simultaneous determination of Zilpaterol and other $\beta$-agonists in calf eye by gas chromatography/tandem mass spectrometry. J AOAC Int 86 : $8-14$

2. Strydom PE, Frylinck L, Montgomery JL, Smith MF (2009) The comparison of three $\beta$-agonists for growth performance, carcass characteristics and meat quality of feedlot cattle. Meat Sci 81: 557-564

3. Kuiper HA, Noordam MY, Dooren-Filpsen MMH, Schilt R, Roos AH (1998) Illegal use of beta-adrenergic agonists: European Community. J Anim Sci 76:195-207

4. Commission decision 1996/23/EC. (1996) Off J Eur Commun L125: 10

5. (2002) MOA Regulation 176. Ministry of Agriculture, P.R. China

6. Xu Z, Hu Y, Li G (2010) Investigation of ractopamine molecularly imprinted stir bar sorptive extraction and its application for trace analysis of $\beta$-agonist s in complex samples. J Chromatogr A 1217: 3612-3618

7. Hu YL, Liu R, Li Y, Li GK (2010) Investigation of ractopamine imprinted polymer for the extraction and analysis of $\beta$-agonists in pig tissues. J Sep Sci 33:2017-2025

8. Wang PL, Fan L, Su XO, Ye ZH (2012) Determination of four kinds of $\beta$-agonists in swine urine by molecularly imprinted solid phase extraction followed gas chromatography coupled mass spectrometry. Chin J Anal Chem 40:470-473

9. Shao B, Jia XF, Zhang J, Meng J, Wu YN, Duan HJ, Tu XM (2009) Multi-residual analysis of $16 \beta$-agonists in pig liver, kidney and muscle by ultra performance liquid chromatography tandem mass spectrometry. Food Chem 114:1115-1121

10. Wang W, Zhang Y, Wang J, Shi X, Ye JN (2010) Determination of $\beta$-agonists in pig feed, pig urine and pig liver using capillary electrophoresis with electrochemical detection. Meat Sci 85:302-305

11. Wang P, Zhu HX, Zhang W, Ye ZH, Zhu RH, Su X (2013) Synthesis of ractopamine molecularly imprinted membrane and its application in the rapid determination of three $\beta$-agonists in porcine urine samples. J Sep Sci 36:1455-1462

12. Posyniak A, Zmudzki J, Niedzielska J (2003) Screening procedures for clenbuterol residue determination in bovine urine and liver matrices using enzyme-linked immunosorbent assay and liquid chromatography. Anal Chim Acta 483:61-67

13. Collins S, Okeeffe M, Smyth MR (1994) Multi-residue analysis for $\beta$-agonists in urine and liver samples using mixed phase columns with determination by radioimmunoassay. Analyst 119:2671-2674

14. He P, Wang Z, Zhang L, Yang W (2009) Development of a labelfree electrochemical immunosensor based on carbon nanotube for rapid determination of clenbuterol. Food Chem 112:707-714

15. Kong J, Jiang L, Su X, Qin J, Du Y, Lin B (2009) Integrated microfluidic immunoassay for the rapid determination of clenbuterol. Lab Chip 9:1541-1547

16. Zhu G, Hu Y, Gao J, Zhong L (2011) Highly sensitive detection of clenbuterol using competitive surface-enhanced Raman scattering immunoassay. Anal Chim Acta 697:61-66 
17. Zhang X, Zhao H, Xue Y, Wu Z, Zhang Y, He Y, Li X, Yuan Z (2012) Colorimetric sensing of clenbuterol using gold nanoparticles in the presence of melamine. Biosens Bioelectron 34:112-117

18. Wang P, Su X, Shi L, Yuan Y (2016) An aptamer based assay for the $\beta$-adrenergic agonist ractopamine based on aggregation of gold nanoparticles in combination with a molecularly imprinted polymer. Microchim Acta 183:2899-2905

19. Cao XL, Li HW, Lian LL, Xu N, Lou DW, Wu YQ (2015) A dualresponsive fluorescence method for the detection of clenbuterol based on BSA-protected gold nanoclusters. Anal Chim Acta 871: $43-50$

20. Cao H, Yuan M, Wang LL, Yu JS, Xu F (2015) Coupling purification and in situ immobilization process of monoclonal antibodies to clenbuterol for immunosensor application. Anal Biochem 476:5966

21. Xu Y, Liu M, Kong N, Liu J (2016) Lab-on-paper micro- and nanoanalytical devices:fabrication, modification, detection and emerging applications. Microchim Acta 183:1521-1542

22. Khamta Y, Pattarawarapan M, Nangola S, Tayapiwatana C (2009) Development of immunochromatographic assay for the on-site detection of salbutamol. J Immunoass Immunochem 30:441-456

23. Zhang G, Wang X, Yang J, Yang Y, Xing G, Li Q, Zhao D, Chai S, Guo J (2006) Development of an immunochromatographic lateral flow test strip for detection of $\beta$-adrenergic agonist Clenbuterol residues. J Immunol Methods 312:27-33

24. Xu W, Chen X, Huang X, Yang W, Liu C, Lai W, Xu H, Xiong Y (2013) $\mathrm{Ru}($ phen)3(2+) doped silica nanoparticle based immunochromatographic strip for rapid quantitative detection of $\beta$-agonist residues in swine urine. Talanta 114:160-166

25. Song C, Zhi A, Liu Q, Yang J, Jia G, Shervin J, Tang L, Hu X, Deng $\mathrm{R}, \mathrm{Xu} \mathrm{C}$, Zhang G (2013) Rapid and sensitive detection of $\beta$ - agonists using a portable fluorescence biosensor based on fluorescent nano silica and a lateral flow test strip. Biosens Bioelectron 50: $62-65$

26. Wang P, Wang Z, Su X (2015) A sensitive and quantitative fluorescent multi-component immuno-chromatographic sensor for $\beta$ agonist residues. Biosens Bioelectron 64:511-516

27. Petruzzelli E, Ius A, Berta S, Dovis M, Albertini A (1996) Preparation and characterization of a monoclonal antibody specific for the $\beta$-agonist clenbuterol. Food Agric Immunol 8:3-10

28. Han J, Gao H, Wang W, Wang Z, Fu Z (2013) Time-resolved chemiluminescence strategy for multiplexed immunoassay of clenbuterol and ractopamine. Biosens Bioelectron 48:39-42

29. Zhang MZ, Wang MZ, Chen ZL, Fang JH, Fang MM, Liu J, Yu XP (2009) Development of a colloidal gold-based lateral-flow immunoassay for the rapid simultaneous detection of clenbuterol and ractopamine in swine urine. Anal Bioanal Chem 395:2591-2599

30. Hu L, Dong T, Zhao K, Deng A, Li J (2017) Ultrasensitive electrochemiluminescent brombuterol immunoassay by applying a multiple signal amplification strategy based on a PAMAM-gold nanoparticle conjugate as the bioprobe and Ag@Au core shell nanoparticles as a substrate. Microchim Acta 184:3415-3423

31. Fu X, Chu Y, Zhao K, Li J, Deng A (2017) Ultrasensitive detection of the $\beta$-adrenergic agonist brombuterol by a SERS-based lateral flow immunochromatographic assay using flower-like gold-silver core-shell nanoparticles. Microchim Acta 184:1711-1719

32. Nielen MWF, Lasaroms JJP, Essers ML, Oosterink JE, Meijer T, Sanders MB, Zuidema T, Stolker AAM (2008) Multiresidue analysis of $\beta$-agonists in bovine and porcine urine, feed and hair using liquid chromatography electrospray ionisation tandem mass spectrometry. Anal Bioanal Chem 391:199-210 